\title{
Effect of Modifying Mechanical Ventilator Trigger Sensitivity on Arterial Blood Gases in ICU Patients
}

\author{
Omnia A.K. Ismail ${ }^{* 1}$, Nessrin G. El-Nahass' ${ }^{1}$, Heba A.A. Abdeen ${ }^{1}$, Youssef M.A. Soliman² \\ ${ }^{1}$ Departments of Physical Therapy for Cardiovascular/Respiratory Disorders and Geriatrics, \\ Faculty of Physical Therapy, Cairo University, Egypt. \\ ${ }^{2}$ Department of Pulmonology, Faculty of Medicine, Cairo University, Egypt \\ *Corresponding author: Omnia A.K. Ismail, Mobile: (+20) 01127000721, E-Mail: mnaomnia@pg.cu.edu.eg
}

\begin{abstract}
Background: Despite the fact that mechanical ventilation is an essential part in management of critically ill patients, mechanically ventilated patients have a higher risk of complications, which can lead to increased morbidity and mortality.

Objective: This study aimed to study the effect of training inspiratory muscle through modifying mechanical ventilator (MV) trigger sensitivity on arterial blood gases in mechanically ventilated patients.

Patients and Methods: Sixty adult patients diagnosed with acute respiratory failure, needed to be intubated and connected to mechanical ventilated. They were from both gender and their ages ranged from 50 to 70 years. The patient were chosen from Intensive Care Unit (ICU), Department of Chest Diseases, Cairo University Hospitals. They were randomly assigned into two equal groups. Group (A): included thirty patients who received training for inspiratory muscle through modifying MV trigger sensitivity plus usual physical therapy. Group (B): included thirty patients who received usual physical therapy only.

Results: The results showed a significant increase in partial arterial pressure $\left(\mathrm{PaO}_{2}\right)$ in both groups, this increasing was significantly higher in patients who received training for the inspiratory muscle plus the usual chest physical therapy than patients who only received usual chest physical therapy (P-value $<0.001)$. The results showed no significant change in neither power of hydrogen $(\mathrm{pH})$ nor partial pressure of carbon dioxide $\left(\mathrm{PaCO}_{2}\right)$. Conclusion: Training to inspiratory muscles in mechanically ventilated patient through modifying mechanical ventilator trigger sensitivity can produce a significant increase in partial arterial pressure $\left(\mathrm{PaO}_{2}\right)$. Although it has no effect in $\mathrm{pH}$ nor $\mathrm{PaCO}_{2}$.
\end{abstract}

Keywords: Arterial blood gases, Inspiratory muscle training, Intensive care unit, Mechanical Ventilation

\section{INTRODUCTION}

Intensive care unit (ICU), often known as critical care unit, is dedicated to the comprehensive management of patients with acute, life-threatening organ dysfunction or who are at risk of developing it. Intensive care employs a variety of technology to help failing organ systems, especially the lungs, cardiovascular system, and kidneys (1).

In intensive care units (ICU), mechanical ventilation (MV) is a very crucial medicine. It used clinically to preserve gas exchange in patients who need assistance in maintaining adequate alveolar ventilation. Although MV can be a life-saving intervention for patients suffering from respiratory failure, MV has been associated with both short- and long-term deleterious consequences ${ }^{(2)}$. In majority of cases, mechanical ventilation is used temporarily, lasting several hours, days, or weeks. The patients should weaned from mechanical ventilation as soon as they can breathe effectively on their own. However, some patients with permanent problems may need to be whole life mechanical ventilation dependent (3).

Physiotherapy has shown to be a crucial component in the management of ICU patients, with both short- and long-term advantages. Physiotherapy for the chest produces physiological changes such as changes in hemodynamic, respiratory, and intracranial parameters ${ }^{(4)}$.
Most ICU patients are required to receive chest physiotherapy procedures such as manual chest manipulation, chest vibrations, chest percussions, manual hyperinflation, posture drainage and various coughing techniques in combination or individually to prevent pulmonary complications ${ }^{(5)}$. In mechanically ventilated patients, chest physical therapy applied aiming to improve airway clearance, thus helping to decrease work of breathing, promote the lungs expansion, and prevent complication ${ }^{(6)}$.

Inspiratory muscle training (IMT) is a technique used to increase the strength and endurance of the diaphragm and other accessory inspiratory muscles ${ }^{(7)}$. Inspiratory muscle training applies a load to the diaphragm and accessory inspiratory muscles to increase their strength and endurance. Training to inspiratory muscle in the ICU have typically applied this load either via external devices that impose resistance or load to inspiratory muscles, or via modification of the mechanical ventilator trigger sensitivity so that patients can only initiate inspiratory flow by generating more negative intrathoracic pressure ${ }^{(8)}$.

Arterial blood gas (ABG) analysis and continuous monitoring is a vital process in identifying and controlling high-risk patients. In arterial blood gases analysis, acid-base balance $(\mathrm{pH})$, partial arterial oxygen 
pressure $\left(\mathrm{PaO}_{2}\right)$, and partial arterial carbon dioxide pressure $\left(\mathrm{PaCO}_{2}\right)$ are measured ${ }^{(9)}$.

This study aimed to study the effect of training inspiratory muscle through modifying mechanical ventilator (MV) trigger sensitivity on arterial blood gases in mechanically ventilated patients.

\section{PATIENTS AND METHODS}

Sixty adult patients, between the ages of 50 and 70 , were mechanically ventilated for more than 48 hours after being diagnosed with acute respiratory failure. They were from both gender. They were chosen from Intensive Care Unit, Department of Chest Diseases, Cairo University Hospitals. The research was carried out between August 2020 and July 2021.

Patients who met the following criteria were chosen to participate in this study: The patients were diagnosed with acute respiratory failure due to chronic obstructive pulmonary diseases (COPD) exacerbation and required mechanical ventilation for more than 48 hours. Their age were between 50 and 70 . They were vitally stable. They were conscious and could respond to verbal command. All the patients can tolerate pressure support (PS) mode of MV with this setting (Positive end-expiratory pressure (PEEP)) less than $8 \mathrm{~cm} \mathrm{H}_{2} \mathrm{O}, \mathrm{FiO}_{2} 0.4$ or less, $\mathrm{SpO}_{2}$ higher than 90).

The patient was ruled out of the study if met one of the following criteria: Poor attention and lack of cooperation, unstable neurological problems, unstable hemodynamics, and missing more than five sessions.

\section{Ethical consideration:}

For patients or their guardians, the potential dangers and advantages were completely explained. They signed a consent document. The confidentiality of the information was guaranteed. The work was approved by the Academic and Ethical Committees at Cairo University. This work has been carried out in accordance with The Code of Ethics of the World Medical Association (Declaration of Helsinki) for studies involving humans.

The participant were randomly assigned into two equal groups:

Group (A): Included 30 patients who received training to inspiratory muscle through modifying mechanical ventilator trigger sensitivity beside usual chest physical therapy.

\section{The training to inspiratory muscle was performed as the following:}

(1) Elevating the head of the bed to angle higher than 45 degrees. (2) Describing the technique to the patient. (3) Measure the maximal inspiratory pressure to the patient. "from lung mechanics in the MV itself". (4) Shifting the mode of MV to pressure support PS mode, then changing the trigger sensitivity to $40 \%$ of maximal inspiratory pressure measured for the patient ${ }^{(8,9)}$. (5) Instruct the patient to inhale as maximally as he/she can after maximal expiration. (6) The training comprised of 4-5 sets, with each set asking the patient to take 6 to 10 breaths. As needed, the patient could take rest between sets; the mode of MV may be altered to the prior mode during the rest ${ }^{(\mathbf{9})}$. Group (B): Included 30 patients who received only the usual chest physical therapy.

The following techniques were used as a usual chest physical therapy depending on patient's requirements: (1) Postural drainage or modified postural drainage according to the patient's needs. (2) Percussion: applied with a "cupped-hand position" on the chest wall, applied for two and half minutes for every lung segment. Its frequency should be 3-7 beats per second. (3) Vibration: therive 717 mechanical vibrator was used. It was placed on the chest wall (anterior, lateral and posterior). If the patient had accumulation of secretion, technique was applied on affected segment for about 5 minutes. (4) Muscle training for upper and lower limbs: for 10 minutes $^{(\mathbf{1 0})}$.

The session was ended if the patient displayed any of the following symptoms:

(1) Increasing respiratory rate to higher than 35 breath/minute (2) Decreeing of saturation to less than 90 . (3) Rising of heart rate to higher than 120 beat/minute. (4) Increasing in systolic blood pressure to higher than 180 $\mathrm{mmHg}$ or dropping to lower than $90 \mathrm{mmHg}$. (5) Paradoxical breathing.

Arterial blood gases $\left(\mathrm{pH}, \mathrm{PaO}_{2}\right.$ and $\left.\mathrm{PaCO}_{2}\right)$ were measured before the study and at end of the study "at time of weaning or after 10 days of training for failed weaning patients".

\section{Statistical analysis}

The collected data were coded, processed and analyzed using the SPSS (Statistical Package for the Social Sciences) version 25 for Windows ${ }^{\circledR}$ (IBM SPSS Inc, Chicago, IL, USA). Quantitative data were expressed as mean \pm standard deviation and were compared by independent t-test when comparing the 2 groups or the paired t-test when comparing between pre and posttreatment in the same group. Qualitative data were expressed as number and percentage and were compared by Chi-squared test. $\mathrm{P}$ value $<0.05$ was considered significant.

\section{RESULTS}

\section{Subject characteristics:}

There was no significant variation in age or sex between both groups (Table 1). 
Table (1): Age and gender characteristics of participants

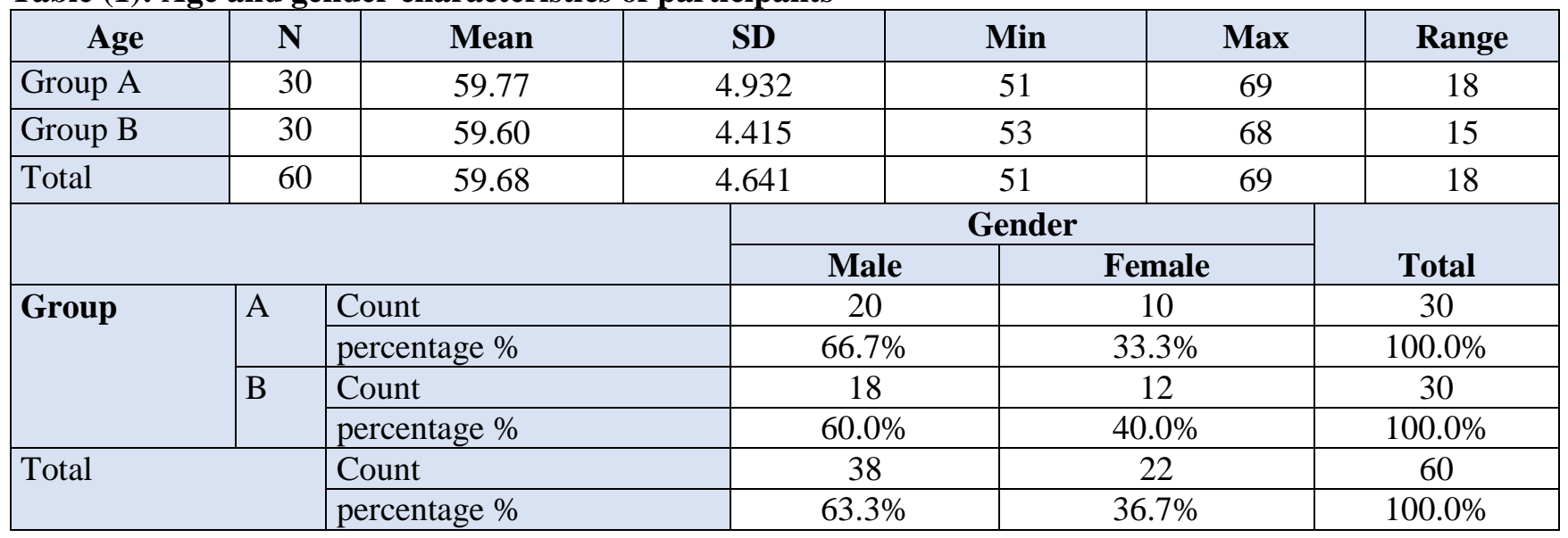

\section{Treatment effects:}

1- pH:

There was no significant difference in pre- and post-treatment $\mathrm{pH}$ between both groups (Table 2).

Table (2): Descriptive statistic and independent samples test for $\mathrm{pH}$

\begin{tabular}{|c|c|c|c|c|c|}
\hline \multicolumn{3}{|l|}{ Groups } & Mean & \multicolumn{2}{|c|}{ SD } \\
\hline \multirow[t]{2}{*}{ Pre pH } & \multicolumn{2}{|l|}{ A } & 7.380 & \multicolumn{2}{|c|}{0.033} \\
\hline & \multicolumn{2}{|l|}{ B } & 7.379 & \multicolumn{2}{|c|}{0.027} \\
\hline \multirow[t]{4}{*}{ Post pH } & \multicolumn{2}{|l|}{ A } & 7.378 & \multicolumn{2}{|c|}{0.016} \\
\hline & \multicolumn{2}{|l|}{$\mathrm{B}$} & 7.380 & \multicolumn{2}{|c|}{0.021} \\
\hline & \multicolumn{2}{|c|}{ Levene's Test } & \multicolumn{3}{|c|}{ t-test } \\
\hline & $\mathrm{F}$ & $\mathrm{P}$ & $\mathrm{t}$ & Mean difference & $\mathrm{P}$ (2-tailed) \\
\hline \multirow{2}{*}{$\begin{array}{l}\text { Pre pH } \\
\text { Post pH }\end{array}$} & 1.013 & 0.318 & 0.170 & 0.001 & 0.866 \\
\hline & 2.365 & 0.130 & -0.473 & -0.002 & 0.638 \\
\hline
\end{tabular}

There was no significant difference between pre and post treatment in both groups as regard $\mathrm{pH}$ (Table 3).

Table (3): Paired sample t-test to compare pre and post treatment $\mathbf{p H}$

\begin{tabular}{|c|c|c|c|c|}
\hline Group & Mean difference & \% of change & $\mathbf{t}$ & P (2-tailed) \\
\hline A & 0.002 & 0.03 & 0.35 & 0.72 \\
\cline { 2 - 5 } & 0.001 & 0.01 & -0.22 & 0.83 \\
\hline
\end{tabular}

2- $\mathrm{PaO}_{2}$ :

There was no significant difference in pre-treatment $\mathrm{PaO}_{2}$ between both groups. However there was a significant difference in post-treatment $\mathrm{PaO}_{2}$ between the 2 groups (Table 4).

Table (4): Descriptive statistic and independent samples test for $\mathrm{PaO}_{2}$

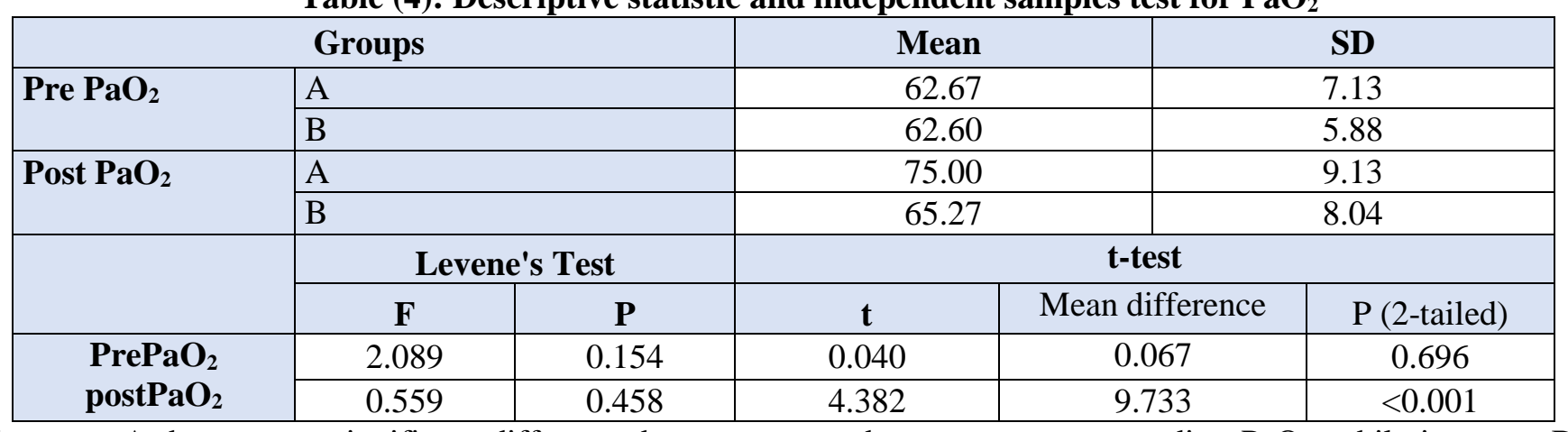

In group $\mathrm{A}$ there was a significant difference between pre and post treatment regarding $\mathrm{PaO}_{2}$, while in group $\mathrm{B}$ the difference was insignificant (Table 5). 
Table (5): Paired sample t-test to compare pre and post treatment $\mathrm{PaO}_{2}$

\begin{tabular}{|c|c|c|c|c|}
\hline Group & Mean difference & \% of change & $\mathbf{t}$ & P (2-tailed) \\
\hline $\mathbf{A}$ & 12.33 & 19.67 & 7.68 & $<0.001$ \\
\cline { 2 - 5 } B & 2.67 & 4.27 & 1.74 & 0.092 \\
\hline
\end{tabular}

3- PaCO2:

There was no significant difference in pre- and post-treatment $\mathrm{PaCO}_{2}$ between both groups (Table 6).

Table (6): Descriptive statistic and independent samples test for $\mathrm{PaCO}_{2}$

\begin{tabular}{|c|c|c|c|c|c|}
\hline \multicolumn{3}{|l|}{ Groups } & \multicolumn{2}{|c|}{ Mean } & SD \\
\hline \multirow[t]{2}{*}{ Pre $\mathrm{PaCO}_{2}$} & \multicolumn{2}{|l|}{ A } & \multicolumn{2}{|c|}{38.97} & 4.38 \\
\hline & \multicolumn{2}{|l|}{$\mathrm{B}$} & \multicolumn{2}{|c|}{40.07} & 4.29 \\
\hline \multirow[t]{4}{*}{ Post $\mathrm{PaCO}_{2}$} & \multicolumn{2}{|l|}{ A } & \multicolumn{2}{|c|}{39.77} & 2.81 \\
\hline & \multicolumn{2}{|l|}{ B } & \multicolumn{2}{|c|}{40.80} & 3.43 \\
\hline & \multicolumn{2}{|c|}{ Levene's Test } & \multicolumn{3}{|c|}{ t-test for Equality of Means } \\
\hline & $\mathbf{F}$ & $\mathbf{P}$ & $\mathbf{t}$ & $\begin{array}{c}\text { Mean } \\
\text { difference }\end{array}$ & $\mathrm{P}$ (2-tailed) \\
\hline Pre $\mathrm{PaCO}_{2}$ & 0.248 & 0.621 & -0.983 & -1.100 & 0.330 \\
\hline Post $\mathrm{PaCO}_{2}$ & 1.133 & 0.291 & -1.276 & -1.033 & 0.207 \\
\hline
\end{tabular}

There was no significant difference between pre and post treatment in both groups as regard $\mathrm{PaCO}_{2}(\mathrm{Table} 7)$.

Table (7): Paired ample t- test to compare pre and post treatment $\mathrm{PaCO}_{2}$

\begin{tabular}{|c|c|c|c|c|}
\hline Group & Mean difference & \% of change & $\mathbf{t}$ & P (2-tailed) \\
\hline $\mathbf{A}$ & 0.80 & 2.05 & 0.86 & 0.39 \\
\cline { 2 - 5 } $\mathbf{B}$ & 0.73 & 1.82 & 0.77 & 0.45 \\
\hline
\end{tabular}

\section{DISCUSSION}

Approximately $40 \%$ of patients who are admitted to intensive care unit (ICU) require mechanical ventilation at some stage of their treatment. Those patient who received mechanical ventilation support are at higher risk to develop chest infections, atelectasis, as well as sputum retentions, which make weaning from mechanical ventilation more difficult and result in higher morbidity and mortality rate ${ }^{(\mathbf{1 0})}$.

The results of this study confirmed that in mechanically ventilated patients, training the inspiratory muscles through modifying mechanical ventilator trigger sensitivity in addition to usual chest physical therapy is more effective in increasing $\mathrm{PaO}_{2}$ than only using usual chest physical therapy. The result also showed that, neither training to inspiratory muscle nor usual chest physical therapy has effect on $\mathrm{pH}$ or $\mathrm{PaCO}_{2}$.

This result agreed with the result in a study by Elbouhy $\boldsymbol{e t}$ al. (11) who studied the effect of training inspiratory muscles in mechanically ventilated COPD patients through adjusting mechanical ventilator trigger sensitivity. In their study they found that the training of inspiratory muscles is effective in increasing $\mathrm{PaO}_{2}, \mathrm{O}_{2}$ saturation, tidal volume $\mathrm{TV}$ and maximal inspiratory pressure (MIP). And also effective in decreasing respiratory rate (RR) and facilitate weaning form mechanical ventilation. Unfortunately they did not include neither $\mathrm{pH}$ nor $\mathrm{PaCO}_{2}$ in their study.

Also the finding of this study coincided with result in study by Ibrahiem et al. ${ }^{(\mathbf{1 2})}$. Who studied the effect of respiratory muscle training on mechanically ventilated patients. In their study the training applied through an external device (Threshold inspiratory muscle training IMT device) and the result of their study showed a significant increase in oxygenation parameter $\left(\mathrm{PaO}_{2}, \mathrm{P} / \mathrm{F}\right.$ ratio and oxygen saturation) on both study and control group but the increasing was significantly higher in study group, also their result showed a significant improving "increasing" in negative inspiratory pressure NIP.

This also coincide with Abd El-Kader ${ }^{(13)}$ who have studied the effect of resistive respiratory muscle training on patients with complete spinal cord injury at the levels from $\mathrm{C} 5$ to $\mathrm{C} 8$. The training applied by using threshold positive expiratory pressure device. The training continued for six weeks. The result of their study showed a significant increase in $\mathrm{PaO}_{2}$, also there were a significant increase "improve" in forced vital capacity (FVC), forced expiratory volume in the first second (FEV1). 
In contrast to the finding in the present study, the result of the study by Abd El- Kader ${ }^{(13)}$ showed a significant reduction in both $\mathrm{PaCO}_{2}$ and $\mathrm{pH}$. This variation in result regarding $\mathrm{PaCO}_{2}$ and $\mathrm{pH}$ may be due to the variation in patient group who had spinal cord injury in their study while in the present study the patient group was acute respiratory failure patients. Also there are a variation in method of applying the training, which is in Abd El-Kader study ${ }^{(\mathbf{1 3})}$ was performed by external device (threshold positive expiratory pressure device); the training with this device apply loading to expiratory muscle more than inspiratory muscles while in the present study the training was applied by modifying mechanical ventilation trigger sensitivity, which apply more load in inspiratory muscle rather than expiratory one.

Abdeen et al. ${ }^{(14)}$ studied the acute effect of chest physical therapy on patients on mechanically ventilation. In their study, there was a significant increase in $\mathrm{PaO}_{2}$ and oxygen saturation $\left(\mathrm{SpO}_{2}\right)$ and they also found no significant change in $\mathrm{pH}$, which agreed with the finding in this present study. However the result of their study showed a significant reduction in $\mathrm{PaCO}_{2}$, which disagreed with the finding in the present study. This may be due to the variation in time of measuring variable i.e. in Abdeen et al. ${ }^{(14)}$, study the arterial blood gases were measured immediately after the session to detect the acute effect of the treatment.

In a study by Farag et al $^{\left({ }^{(15)}\right.}$ they studied the effect of training inspiratory muscle on COPD patient. The training was applied through threshold inspiratory muscles training IMT device. The result in their study showed a significant increase in $\mathrm{PaO}_{2}$ in the study group, which agreed with finding in present study, but in contrast the result of their study showed a significant decrease in $\mathrm{PaCO}_{2}$ and significant increase in $\mathrm{pH}$ which disagreed with the finding in this present study. This variation in result may be due to the difference between patients group i.e. in their study although the patients were diagnosed with COPD but their condition were not exacerbated and they were not on mechanical ventilation support. Also there are a difference in duration of applying the training, the duration of present study were around a week while in Farag et $\boldsymbol{a l} .{ }^{(15)}$ study the training duration was two months.

\section{CONCLUSION}

Training the inspiratory muscles in mechanically ventilated patients through modifying mechanical ventilator trigger sensitivity can produce a significant increase in $\mathrm{PaO}_{2}$. Although it has no effect on neither $\mathrm{pH}$ nor $\mathrm{PaCO}_{2}$.

Financial support and sponsorship: Nil. Conflict of interest: Nil.

\section{REFERENCES}

1. Kelly F, Fong K, Hirsch $\mathbf{N}$ et al. (2014): Intensive care medicine is 60 years old: the history and future of the intensive care unit. Clinical Medicine (London, England), 14(4): 376-379.

2. Pham T, Brochard L, Slutsky A (2017): Mechanical ventilation: State of the art. Mayo Clinic Proceedings, 92(9): 1382-1400.

3. Hill D, Fowler R, Burns K et al. (2017): Long-term outcomes and health care utilization after prolonged mechanical ventilation. Annals of the American Thoracic Society, 14(3): 355-362.

4. Berney S, Haines K, Denehy L (2012): Physiotherapy in critical care in Australia. Cardiopulmonary physical Therapy Journal, 23(1): 19-25.

5. Spapen H, De Regt J, Honoré P (2017): Chest physiotherapy in mechanically ventilated patients without pneumonia-a narrative review. Journal of Thoracic Disease, 9(1): 44-49.

6. Meawad M, Abd El Aziz A, Obaya H et al. (2018): Effect of chest physical therapy modalities on oxygen saturation and partial pressure of arterial oxygen in mechanically ventilated patients. The Egyptian Journal of Hospital Medicine, 72(8): 5005-5008

7. Shei R, Paris H, Wilhite D et al. (2016): The role of inspiratory muscle training in the management of asthma and exercise-induced bronchoconstriction. The Physician and Sports Medicine, 44(4): 327-334.

8. Elkins M, Dentice R (2015): Inspiratory muscle training facilitates weaning from mechanical ventilation among patients in the intensive care unit: a systematic review. Journal of Physiotherapy, 61(3): 125-134.

9. Sood P, Paul G, Puri S (2010): Interpretation of arterial blood gas. Indian journal of critical care medicine : peerreviewed, official publication of Indian Society of Critical Care Medicine, 14(2): 57-64

10. Ahmed S, Daniel Martin A, Smith B (2019): Inspiratory muscle training in patients with prolonged mechanical ventilation: Narrative review. Cardiopulmonary Physical Therapy Journal, 30(1): 44-50

11. Elbouhy M, AbdelHalim H, Hashem A (2014): Effect of respiratory muscles training in weaning of mechanically ventilated COPD patients. Egypt J Chest Dis Tuberc., 63 (3): 679-687.

12. Ibrahiem A, Mohamed M, Saber H (2014): Effect of respiratory muscles training in addition to standard chest physiotherapy on mechanically ventilated patients. J Med Res Prac., 3: 52-58.

13. Abd El-Kader S (2018): Impact of respiratory muscle training on blood gases and pulmonary function among patients with cervical spinal cord injury. Electronic Journal of General Medicine, 15(3): 15-20.

14. Abdeen H, Elgendy S, Nassef $\mathbf{N}$ et al. (2020): Acute effect of chest physical therapy on arterial blood gases for mechanical ventilated patients. The Medical Journal of Cairo University, 88: 1469-1475.

15. Farag A, Akram A, Al-Sayed A (2007): Effect of inspiratory muscle training on blood gases in patients with chronic obstructive lung disease. Bull Fac $\mathrm{Ph}$ Th Cairo Univ., 12(2): 227-235. 